\title{
Human Embryonic Stem Cell Derived from Early Stage Fertilized Ovum: Non Immunogenic and Universal, Neuronal and Non-neuronal Cell Lines
}

\author{
Geeta Shroff, Arpita Srivastav, Rohan Shroff \\ Nutech Mediworld, New Delhi, India
}

\begin{abstract}
Background: Human embryonic stem cells (hESCs) have the potential to treat various human disorders currently labeled as incurable and/or terminal illness. However, the fear that the patients' immune system would recognize them as non self and lead to an immune rejection has hampered their use. The main cause for immune rejection is usually the incompatibility of both donor and recipient's major histocompatibility complex (MHC).

Methods: We describe a hESC line developed through a patented technology that does not lead to immune reaction upon transplantation. We have transplanted these cells in $>1,400$ patients with chronic/terminal conditions and did not observe any immune reaction. No immunosuppressant were administered to these patients. We analyzed the expression levels of MHC-I and MHC-II on the surface of these hESCs using microarray technology. The gene targets for miRNA were analyzed using Gene ontology and DAVID database and pathways for these genes were determined using Reactome and Panther databases.

Results: Our results showed that the levels of expression of MHC-I and MHC-II on hESCs is almost negligible and thus the hESCs are less susceptible to an immune rejection.

Conclusions: The hESCs cultured at our facility expresses low levels of MHC-I and do not produce an immune reaction. These can be administered universally and need no cross matching before transplantation.
\end{abstract}

Keywords: Human embryonic stem cells, Major histocompatibility complex, DAVID, Microarray technology, Reactome, miRNA

\section{Introduction}

Human Embryonic stem cells (hESCs) are the potential therapeutic targets for various chronic/terminal conditions

Received: November 10, 2017, Revised: January 9, 2018,

Accepted: February 18, 2018, Published online: April 30, 2018

Correspondence to Geeta Shroff

Nutech Mediworld, H-8, Green Park Extension, New Delhi 110016, India

Tel: +91-11-26180039, Fax: +91-11-46067841

E-mail: geetashroff@hotmail.com

(a) This is an open-access article distributed under the terms of the Creative Commons Attribution Non-Commercial License (http://creativecommons.org/ licenses/by-nc/4.0/), which permits unrestricted non-commercial use, distribution, and reproduction in any medium, provided the original work is properly cited.

Copyright (c) 2018 by the Korean Society for Stem Cell Research
(1). hESC lines are excellent candidates in transplantation medicine because they have the capacity to grow indefinitely in culture without losing pluripotency (2). The first FDA approved clinical trial of hESCs therapy was conducted in 2009; a product derived from hESCs was applied for stimulating nerve growth in patients (3). But, the clinical transplantation of hESCs requires immunosuppressive therapy as immune rejection is the bottleneck which hinders the application of hESCs as transplantation therapy (4).

The underline cause of immune rejection are the major histocompatibility antigens (cell surface antigens), essential for the acquired immune system which usually vary between the donor and host as they are perceived as non self by the recipient's immune system $(5,6)$. Swijnenburg and his co-workers proved that the embryonic stem cells 
(ESC) trigger an accelerated infiltration of immune cells, indicating the immune response towards developing ESCs in allotransplant (genetically non-identical) that increases over time (7). Similarly, Fandrich and his co-workers showed that the rat ESC-like cells express very low levels of major histocompatibility complex (MHC) -I antigens and completely lack MHC-II and co stimulatory molecules. This helps to decrease the chances of immune rejection as the donor MHC is absent that could mismatch with the recipient's MHC (8). Low levels of MHC-I result in escape of hESCs from an immune rejection (9). But, low levels of MHC I antigen increases after differentiation both in vitro and in vivo and is sufficient for immune rejection $(10,11)$. The present study describes hESCs of pre-blastomeric origin derived at 2-celled stage and cultured using a patented technology that do not induce any immune rejection. The study also describes the differentially expressed genes profile and their related pathways for immune reactions.

\section{Materials and Methods}

\section{Origin of cell line}

The study was approved by an independent ethics committee (IEC). Cell lines used in this study were cultured from a spare fertilized ovum obtained during natural in vitro fertilization (IVF) process with due consent from the donor. The hESCs were cultured and maintained as per our patented technology (United States Granted Patent No US 8592, 208, 52) in a good manufacturing practice (GMP), good laboratory practice (GLP) and good tissue practice (GTP) compliant laboratory. The cell lines were stable and free from any contamination. The detailed cell culture and differentiation techniques are explained in our previous paper (12).

\section{Cell culture and derivation}

The fertilized ovum was suspended in Roswell Park Memorial Institute medium (RPMI) and broken by mechanical means. $\beta$ hCG and progestin was added and the cells were incubated in a $\mathrm{CO}_{2}$ water jacketed incubator for $24 \mathrm{hrsin}$ an aerobic condition. The cell suspension was divided into two and one of them was re-incubated in the same incubator after adding Dulbecco's Modified Eagle's Medium (DMEM, Himedia Labs, Mumbai, India) and the other in RPMI in anaerobic condition. The details of the cell culture and derivation are detailed in our previous paper (12).

\section{RNA extraction and RT-PCR}

Three samples were selected for the polymerase chain reaction (PCR) analysis and RNA extraction was performed using Qiagen RNeasy micro kit. RNA concentration was estimated using Nanodrop spectrophotometer. RNA purity and integrity were checked by employing an Agilent Bioanalyzer. The cDNA synthesis and primer sequences and annealing temperatures for genes Nestin, Sox 2 , HLA-G and $\beta$-HCG are mentioned in our previous paper (12). $\beta$-actin gene was used as house keeping control gene. The amplified PCR products were analyzed by electrophoresis on $1 \%$ agarose gels.

\section{miRNA microarray analysis}

Samples were hybridized for microarray experiment. microRNA (miRNA) molecules in total RNA were labeled with Agilent miRNA labeling reagent and hybridization kit (Cat \# 5190-0456). Labeling method used ligation of one cyanine 3-pCp molecule to the 3'end of RNA molecule with greater than $90 \%$ efficiency that generates fluorescent miRNA. After hybridization, the samples were scanned with Agilent Scanner. Images were analyzed using Agilent's Feature extraction software. Raw data was normalized using GeneSpring GX 12.6 software. Complete miRNA in the array detected on the basis of intensities.

For filtering the high expression miRNA from complete, lobase 2 value $\geq 0.6$ was used. The target genes for differentially regulated miRNA's for up-regulation and down-regulation were checked using GeneSpring GX 12.6 software with an integrated target scan database.

\section{Functional annotation analysis}

To examine the gene pool of detected miRNA, Database for Annotation, Visualization and Integrated Discovery (DAVID)was used (13). It covers more than 40 annotation categories, including Gene Ontology (GO; www.geneontology.org// terms, protein-protein interactions, protein functional domains, disease associations and biological pathways. GO terms organize genes into hierarchical categories consisting of three main layers and the first layer included three branches: biological process, cellular component and molecular function.

We analyzed the potential target genes associated pathways as per the Kyoto Encyclopedia of Genes and Genomes, Reactome and Panther pathway database (14-16). A p value of $<0.05$ was used as the cut-off criterion.

\section{Results}

The hESC cell line analyzed was a mixture of the two 
cell lines; neuronal and non-neuronal. Thus, the analysis plan is focused on both of them. Mixture batch (M-batch) which is a mixture of both the cell lines was used as a control to compare the analysis of neuronal and non-neuronal cell lines.

\section{Cell line differentiation}

Differentiation of the hESC line into neuronal and nonneuronal cells was observed under appropriate culture conditions on DMEM and RPMI media. The detailed protocol is explained in our previous paper. hESCs expressed high levels of nestin (neuronalprogenital cells, NPCs) and NeuN (neuronal marker undifferentiated cells) which indicates the neuronal differentiation nature of these cells (12).

\section{RNA Quality Control (QC) check}

All the three samples were found to be suitable for microarray experiments as they showed high purity and concentration of RNA.

\section{Surface markers analyzed by RT-PCR}

Markers expression for HLA-G, a major histocompatible factor, 5-methyl cytosine gene activation marker, telomerase maintenance of genomic integrity and pluripotency of stem cells and $\beta$ - human chorionic gonadotropin ( $\beta$-hCG) which is an immune modulator was found to be amplified indicating that these genes are pres- ent and expressive in hESCs at mRNA level. Expression profile of all the markers was explained in our previous paper (12).

\section{miRNA potential target gene analysis}

Hybridized samples predicted the differentially expressed miRNA in the individual test sample. Each miRNA has a unique mirbase accession number and ability to regulate the expression of several hundred target genes. GeneSpring GX provided the gene target and their location on chromosome for each miRNA as shown in Table 1. Hence, GO term and their description for each miRNA target gene was determined for immune reactions.

\section{Functional analysis}

Biological processes of the predicted miRNAs gene targets were classified by GO analysis. Genes involved in each pathway are then determined by Reactome and Panther databases. Significant p-values showed the up and downregulation of genes involved in various pathways of immune rejection (Table 2). After differentiation of the cell lines, MHC-I receptor activity $(\mathrm{p}=0.0059)$, MHC-I protein complex $(p=0.0057)$ and total MHC protein complex $(p=0.0284)$ had statistically significant values, implying that their function and pathways are down-regulated and hence the expression of MHC-I on hESCs is low. Antigen processing and presentation of peptide antigen via MHC-I was significant $(p=0.0269)$ indicating a higher potential

Table 1. Protein coding gene targets for miRNA's analyzed by GeneSpring GX

\begin{tabular}{|c|c|c|c|c|c|c|}
\hline $\begin{array}{l}\text { Sr. } \\
\text { No }\end{array}$ & $\begin{array}{c}\text { Mirbase accession } \\
\text { number }\end{array}$ & $\mathrm{GO}$ term & GO_Process & Full name & $\begin{array}{l}\text { Chromosome } \\
\text { location }\end{array}$ & p-value \\
\hline 1 & MIMAT0005828 & GO:0030183 & B-cell Differentiation & ADP-ribosylation factor-like 1 & 2 & 0.0582 \\
\hline 2 & MIMAT0005828 & GO:0030183 & B-cell Differentiation & $\begin{array}{l}\text { B-cell CLL/lymphoma } 11 \mathrm{~A} \\
\text { (zinc finger protein) }\end{array}$ & 2 & 0.0683 \\
\hline 3 & MIMAT0005828 & GO:0030183 & B-cell Differentiation & $\begin{array}{l}\text { Integrin, beta } 1 \text { (fibronectin receptor, } \\
\text { beta polypeptide, antigen CD29 } \\
\text { includes MDF2, MSK12) }\end{array}$ & 10 & 0.0808 \\
\hline 4 & MIMAT0005828 & GO:0030183 & B-cell Differentiation & Histone deacetylase 4 & 2 & 0.1070 \\
\hline 5 & MIMAT0005828 & GO:0030183 & B-cell Differentiation & $\begin{array}{l}\text { Enhancer binding protein (C/EBP), } \\
\text { gamma }\end{array}$ & 19 & 0.1683 \\
\hline 6 & MIMAT0005828 & GO:0030183 & $\begin{array}{l}\mathrm{T} \text { cell receptor signaling } \\
\text { pathway }\end{array}$ & $\begin{array}{l}\text { Phosphoinositide-3-kinase, } \\
\text { regulatory subunit } 1 \text { (alpha) }\end{array}$ & 5 & 0.1795 \\
\hline 7 & MIMAT0005828 & GO:0030183 & B-cell Differentiation & One cut homeobox 1 & & 0.2662 \\
\hline 8 & MIMAT0005865 & GO:0002520 & $\begin{array}{l}\text { Immune system } \\
\text { development }\end{array}$ & SMAD family member 3 & 15 & 0.6051 \\
\hline 9 & MIMAT0005865 & GO:0042113 & B cell activation & Taxilin alpha & 1 & 0.6462 \\
\hline 10 & MIMAT0005828 & GO:0042113 & $\begin{array}{l}\text { Immune response-activating } \\
\text { signal transduction }\end{array}$ & $\begin{array}{l}\text { src kinase associated } \\
\text { phosphoprotein } 2\end{array}$ & & 0.4767 \\
\hline 11 & $\begin{array}{l}\text { MIMAT0005828, } \\
\text { MIMAT0005878 }\end{array}$ & GO:0042113 & B cell activation & & 7 & 0.3143 \\
\hline
\end{tabular}


Table 2. Transcriptomic Profile of Genes

\begin{tabular}{|c|c|c|c|c|c|c|}
\hline Sr No & GO term & Description & Count & $\%$ & $p$-value & Genes \\
\hline 1 & GO:0030183 & B cell differentiation & 4 & 1.005025 & 0.0678 & BCL2, SP3, BAX, CD79A \\
\hline 2 & GO:0002520 & Immune system development & 9 & 2.261307 & 0.1764 & $\begin{array}{l}\text { HOXA3, BCL2, BAX, CD4, CD79A, } \\
\text { FGF3, ERCC2 }\end{array}$ \\
\hline 3 & GO:0042113 & B cell activation & 4 & 1.005025 & 0.1873 & BCL2, SP3, BAX, CD79A \\
\hline 4 & GO:0001782 & B cell homeostasis & 2 & 0.502513 & 0.1959 & $\mathrm{BCL} 2, \mathrm{BAX}$ \\
\hline 5 & GO:0032943 & Mononuclear cell proliferation & 3 & 0.753769 & 0.2136 & BCL2, BAX, CD79A \\
\hline 6 & GO:0045058 & $\mathrm{T}$ cell selection & 2 & 0.502513 & 0.3139 & $\mathrm{BCL} 2, \mathrm{CD} 4$ \\
\hline 7 & GO:0030217 & $\mathrm{T}$ cell differentiation & 3 & 0.753769 & 0.3657 & $\mathrm{BCL} 2, \mathrm{SP} 3, \mathrm{CD} 4$ \\
\hline 8 & GO:0050870 & Positive regulation of $\mathrm{T}$ cell activation & 3 & 0.753769 & 0.4413 & RARA, CD4, THY1 \\
\hline 9 & GO:0042110 & $\mathrm{T}$ cell activation & 4 & 1.005025 & 0.4509 & $\mathrm{BCL} 2, \mathrm{SP} 3, \mathrm{BAX}, \mathrm{CD} 4$ \\
\hline 10 & GO:0006959 & Humoral immune response & 3 & 0.753769 & 0.4611 & CR2, LY86, BCL2 \\
\hline 11 & GO:0045087 & Innate immune response & 4 & 1.005025 & 0.5109 & CYBA, CR2，IRGM，TBKBP1 \\
\hline 12 & GO:0002429 & $\begin{array}{l}\text { Immune response-activating cell } \\
\text { surface receptor signaling pathway }\end{array}$ & 2 & 0.502513 & 0.5388 & CD79A, THY1 \\
\hline 13 & GO:0002253 & Activation of immune response & 3 & 0.753769 & 0.5535 & CR2, CD79A, THY1 \\
\hline 14 & GO:0045580 & Regulation of $\mathrm{T}$ cell differentiation & 2 & 0.502513 & 0.6367 & CLPTM1, RARA \\
\hline 15 & GO:0002757 & $\begin{array}{l}\text { Immune response-activating signal } \\
\text { transduction }\end{array}$ & 2 & 0.502513 & 0.6439 & CD79A, THY1 \\
\hline 16 & GO:0002764 & $\begin{array}{l}\text { Immune response-regulating signal } \\
\text { transduction }\end{array}$ & 2 & 0.502513 & 0.6711 & CD79A, THY1 \\
\hline 17 & GO:0002684 & $\begin{array}{l}\text { Positive regulation of immune } \\
\text { system process }\end{array}$ & 5 & 1.256281 & 0.6905 & CR2, RARA, CD4, CD79A, THY1 \\
\hline 18 & GO:0002252 & Immune effector process & 3 & 0.753769 & 0.7428 & CPLX2, CR2, BCL2 \\
\hline 19 & GO:0050778 & $\begin{array}{l}\text { Positive regulation of immune } \\
\text { response }\end{array}$ & 3 & 0.753769 & 0.7811 & CR2, CD79A, THY1 \\
\hline 20 & GO:0002443 & Leukocyte mediated immunity & 2 & 0.502513 & 0.8191 & CPLX2, CR2 \\
\hline 21 & GO:0050776 & Regulation of immune response & 4 & 1.005025 & 0.8240 & CR2, RARA, CD79A, THY1 \\
\hline 22 & GO:0042287 & MHC protein binding & 1 & 0.251256 & 1.0000 & $\mathrm{CD} 4$ \\
\hline 23 & GO:0042289 & MHC class II protein binding & 1 & 0.251256 & 1.0000 & CD4 \\
\hline 24 & GO:0032395 & MHC class II receptor activity & 1 & 0.251256 & 1.0000 & HLA-DRB1 \\
\hline 25 & GO:0019815 & B cell receptor complex & 1 & 0.251256 & 1.0000 & CD79A \\
\hline 26 & GO:0019814 & Immunoglobulin complex & 1 & 0.251256 & 1.0000 & CD79A \\
\hline 27 & GO:0042613 & MHC class II protein complex & 1 & 0.251256 & 1.0000 & HLA-DRB1 \\
\hline 28 & GO:0042612 & MHC class I protein complex & 9 & 0.418994 & 0.0057 & $\begin{array}{l}\text { AZGP1, MICA, ULBP1, ULBP2, HLA-A, } \\
\text { HFE, HLA-C, HLA-G, HLA-F }\end{array}$ \\
\hline 29 & GO:0032393 & MHC class I receptor activity & 7 & 0.325885 & 0.0059 & $\begin{array}{l}\text { MICA, ULBP1, ULBP2, HLA-A, HLA-C, } \\
\text { HLA-G, HLA-F }\end{array}$ \\
\hline 30 & GO:0002474 & $\begin{array}{l}\text { Antigen processing and presentation of } \\
\text { peptide antigen via MHC class I }\end{array}$ & 1 & 0.263158 & 1.0000 & HLA-E \\
\hline
\end{tabular}

Count- Number of genes in the respective term. \%- Percentage of involved genes/total genes.

of MHC-I to process the antigen only if they are present on hESCs. MHC -II receptor activity, and for protein binding in MHC-II class protein showed down-regulation $(p=1.000)$ which states that the hESCs did not express MHC-II. Our results clearly prove that B-cell lymphoma-2 (BCL 2) is involved in $\mathrm{B}$ cell lineage commitment $(p=1.00)$, B cell differentiation $(p=0.0678)$, B cell activation $(p=0.1873)$, B cell homeostasis $(p=0.1959)$, T cell selection, differentiation and activation $(p=0.4509)$, humoral immune response $(\mathrm{p}=0.4611)$ and all these processes are down-regulated indicating that these functional processes are absent in hESCs. Thymocyte differentiation antigen 1 (THY1) is involved in immune system development $(p=0.1764)$, immune surface receptor signaling pathway $(p=0.5388)$, activation of immune response $(p=0.5535)$, positive regulation of immune system process $(p=0.6905)$, regulation of immune response $(p=0.8240)$ and for all these processes GO analysis showed the down-regulation suggesting that the immune response to hESCs is down-regulated by THY1. 


\section{Discussion}

Since hESCs were first isolated, it has been widely accepted that these cells hold the potential to change the face of medicine as they have the capacity to differentiate in every cell type of the human body (17). But, the immune rejection by the patients' immune system acts as a barrier to the hESC therapy (18).

Previous experiments conducted by Drukker and his co-workers observed that in the mouse strains with different types of immune deficiency, $\mathrm{T}$ cell-deficient animals failed to reject hESC-derived graft, whereas the lack of NK cells or B-cells did not interfere with hESC rejection; thus suggesting that $\mathrm{T}$ cells play a pivotal role in the rejection of hESCs and their differentiated derivatives (19). Our results showed a down regulation for $\mathrm{T}$ cell activation indicating that the hESCs are unable to induce proliferation of $\mathrm{T}$ cell population in the host, thus, these hESCs can easily escape immune rejection pathway. It has also been proven that hESCs are able to inhibit $\mathrm{T}$ cell proliferation in response to allogeneic antigen presenting dendritic cell (20). Immune system is regulated by several genes but BCL 2 plays a major role. BCL 2 is an anti-apoptotic gene and it regulates cell differentiation processes. Our results showed that BCL 2 down regulates the B-cell and T-cell activation; thus, the functional processes of B-cell and T-cell activation are absent in hESCs.

It was recently suggested that immunological maturity or expression of antigens on the surface of hESCs is a late event during the gestational period of human embryos (21). Our microarray data support this notion. The expression of immune related genes, MHC-I and MHC-II was not up-regulated during in vitro differentiation of hESCs. These hESCs were of pre-blastomeric origin and at 2-celled stage; wherein the levels of expression of MHC-I and MHC-II are almost negligible (12). Besides, hESCs might provoke less of an immune response because expression of MHC-I and MHC-II protein was not detected on the surface of either undifferentiated or their differentiated progeny (20) But, hESCs express high levels of MHC-I after differentiation both in vitro and in vivo hence hESCs can be rejected on transplantation (9). However, our results proved that after pre differentiation, the expression of $\mathrm{MHC}$ class I protein complex $(p=0.0057)$, and MHC class I receptor activity $(p=0.0059)$ showed a down-regulation which means that hESCs grown at our facility showed low levels of MHC-I and MHC-II even after differentiation and hence are capable to escape an immune rejection. We have transplanted these cell lines in over 1,400 patients with terminal conditions where the traditional therapies had not worked and found them to be safe and effective. For all these patients, we did not observe an immune reaction. We have never administered any immunosuppressant to these patients (22-26).

Another key player of immune system activation is THY1 also known as CD90. It is a cell surface antigen which has neuronal expression in nervous system and is found to activate the immune system processes. Since, hESCs have no antigens expressed on their surface and are not involved in any immune reaction; thus, the host cells are not able to identify the injected hESC as foreign and the pathway for immune rejection is down-regulated.

\section{Conclusion}

The present study revealed that the hESCs cultured at our facility are non-immunogenic as they express very low levels of MHC-I and MHC-II. These hESCs found to be suitable for transplantation without the use of immunosuppressant and are universal in their applicability.

\section{Acknowledgments}

The author acknowledges Knowledge Isotopes Pvt. Ltd. (http://www.knowledgeisotopes.com) for the medical writing assistance.

\section{Potential Conflict of Interest}

The authors have no conflicting financial interest.

\section{References}

1. Thomson JA, Itskovitz-Eldor J, Shapiro SS, Waknitz MA, Swiergiel JJ, Marshall VS, Jones JM. Embryonic stem cell lines derived from human blastocysts. Science 1998;282: 1145-1147

2. Batten P, Rosenthal NA, Yacoub MH. Immune response to stem cells and strategies to induce tolerance. Philos Trans R Soc Lond B Biol Sci 2007;362:1343-1356

3. Alper J. Geron gets green light for human trial of ES cell-derived product. Nat Biotechnol 2009;27:213-214

4. Gage FH. Cell therapy. Nature 1998;392(6679 Suppl):18-24

5. Menendez P, Bueno C, Wang L, Bhatia M. Human embryonic stem cells: potential tool for achieving immunotolerance? Stem Cell Rev 2005;1:151-158

6. Roopenian D, Choi EY, Brown A. The immunogenomics of minor histocompatibility antigens. Immunol Rev 2002; 190:86-94

7. Swijnenburg RJ, Schrepfer S, Govaert JA, Cao F, Ransohoff $\mathrm{K}$, Sheikh AY, Haddad M, Connolly AJ, Davis MM, Robbins RC, Wu JC. Immunosuppressive therapy mitigates immunological rejection of human embryonic stem cell xenografts. Proc Natl Acad Sci U S A 2008;105:12991-12996

8. Fändrich F, Lin X, Chai GX, Schulze M, Ganten D, Bader 
M, Holle J, Huang DS, Parwaresch R, Zavazava N, Binas B. Preimplantation-stage stem cells induce long-term allogeneic graft acceptance without supplementary host conditioning. Nat Med 2002;8:171-178

9. Drukker M, Katz G, Urbach A, Schuldiner M, Markel G, Itskovitz-Eldor J, Reubinoff B, Mandelboim O, Benvenisty $\mathrm{N}$. Characterization of the expression of MHC proteins in human embryonic stem cells. Proc Natl Acad Sci U S A 2002;99:9864-9869

10. Drukker M, Katchman H, Katz G, Even-Tov Friedman S, Shezen E, Hornstein E, Mandelboim O, Reisner Y, Benvenisty N. Human embryonic stem cells and their differentiated derivatives are less susceptible to immune rejection than adult cells. Stem Cells 2006;24:221-229

11. Reynolds BA, Weiss S. Generation of neurons and astrocytes from isolated cells of the adult mammalian central nervous system. Science 1992;255:1707-1710

12. Shroff G. Establishment and characterization of a neuronal cell line derived from a 2-cell stage human embryo: clinically tested cell-based therapy for neurological disorders. International Journal of Recent Scientific Research 2015; 6:3730-3738

13. DAVID. [cited 2017 May 1]. Available from: https://david-d.ncifcrf.gov/

14. KEGG. [cited 2017 Apr 18]. Available from: www.genome.ad.jp/kegg.

15. Panther. [cited 2017 May 11]. Available from: http:// pantherdb.org/.

16. Reactome. [cited 2017 May 5]. Available from: http:// www.reactome.org.
17. Odorico JS, Kaufman DS, Thomson JA. Multilineage differentiation from human embryonic stem cell lines. Stem Cells 2001;19:193-204

18. Rogers NJ, Lechler RI. Allorecognition. Am J Transplant 2001;1:97-102

19. Drukker M. Immunogenicity of human embryonic stem cells: can we achieve tolerance? Springer Semin Immunopathol 2004;26:201-213

20. Li L, Baroja ML, Majumdar A, Chadwick K, Rouleau A, Gallacher L, Ferber I, Lebkowski J, Martin T, Madrenas J, Bhatia M. Human embryonic stem cells possess immune-privileged properties. Stem Cells 2004;22:448-456

21. Dekel B, Burakova T, Arditti FD, Reich-Zeliger S, Milstein O, Aviel-Ronen S, Rechavi G, Friedman N, Kaminski N, Passwell JH, Reisner Y. Human and porcine early kidney precursors as a new source for transplantation. Nat Med 2003;9:53-60

22. Shroff G. Human embryonic stem cell for the treatment of multiple sclerosis: A case report. Case Rep Int 2015;4:38-42

23. Shroff G. Therapeutic potential of human embryonic stem cells in type 2 diabetes mellitus. World J Stem Cells 2016;8:223-230

24. Shroff G, Das L. Human embryonic stem cell therapy in cerebral palsy children with cortical visual impairment: a case series of 40 patients. J Cell Sci Ther 2014;5:189

25. Shroff G, Gupta R. Human embryonic stem cells in the treatment of patients with spinal cord injury. Ann Neurosci 2015;22:208-216

26. Shroff G, Gupta R, Zadeng L. Human embryonic stem cell therapy for aplastic anemia. Clin Case Rep 2017;5:919-922 